\title{
Au@Ag Heterogeneous Nanorods as Nanozyme Interfaces with Peroxidase-Like Activity and Their Application for One-Pot Analysis of Glucose at Nearly Neutral pH
}

Lei Han, ${ }^{\dagger, \ddagger}, \|$ Cuncheng Li, ${ }^{\S} \|$ Tao Zhang, ${ }^{\S}$ Qiaolin Lang, ${ }^{\dagger}$ and Aihua Liu*, ${ }^{\dagger, \ddagger}$

${ }^{\dagger}$ Laboratory for Biosensing, and Key Laboratory of Biofuels, Qingdao Institute of Bioenergy \& Bioprocess Technology, Chinese Academy of Sciences, 189 Songling Road, Qingdao 266101, China

${ }^{\ddagger}$ University of Chinese Academy of Sciences, 19A Yuquan Road, Beijing 100049, China

${ }^{\S}$ Key Laboratory of Chemical Sensing \& Analysis in Universities of Shandong, School of Chemistry and Chemical Engineering, University of Jinan, Jinan 250022, China

\section{Supporting Information}

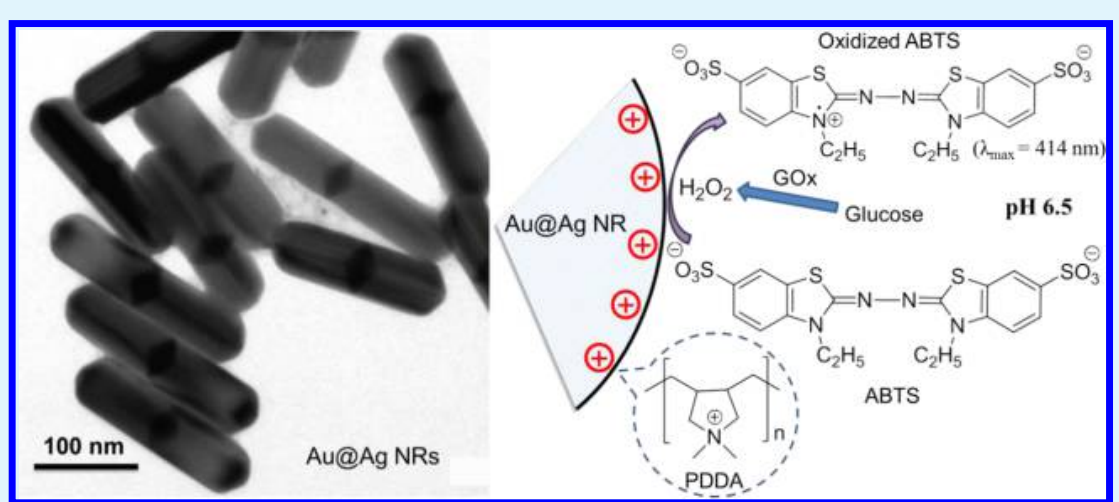

ABSTRACT: As substitutes for natural peroxidases, most nanomaterial-based enzyme mimetics (nanozymes) have unique properties such as high stability, low-cost, large surface area, and high catalytic activity. However, they usually work in acidic conditions and thus impede their real applications. In this work, by modulating the nanostructure, composition, and surface property of the bimetallic materials, the positively charged poly(diallyldimethylammonium)-stabilized Au@Ag heterogeneous nanorods (NRs) were developed as synergistic peroxidase-like interfaces, which exhibited high activity over a wide $\mathrm{pH}$ range $(\mathrm{pH}$ 4.0-6.5) using 2,2' -azino-bis(3-ethylbenzthiazoline-6-sulfonic acid) diammonium salt (ABTS) as the chromogenic substrate. At $\mathrm{pH}$ 6.5, the peroxidase-like activity for the $\mathrm{Au} @ \mathrm{Ag}$ heterogeneous NRs was stable and optimal within $20-40{ }^{\circ} \mathrm{C}$. Moreover, the Au@Ag heterogeneous NRs showed excellent temperature stability and long-term storage stability. Given these characters, the detection of $\mathrm{H}_{2} \mathrm{O}_{2}$ at $\mathrm{pH} 6.5$ was proposed on the basis of the Au@Ag heterogeneous NRs catalyzing the colorimetric reaction of $\mathrm{H}_{2} \mathrm{O}_{2}$ and ABTS, where the oxidized ABTS showed a typical absorption peak at $414 \mathrm{~nm}$. The absorbance at $414 \mathrm{~nm}$ was linear with $\mathrm{H}_{2} \mathrm{O}_{2}$ concentration from 0.01 to $10 \mathrm{mM}$. Further, considering that Au@Ag heterogeneous NRs and glucose oxidase (GOx) have similar optimal $\mathrm{pH}$ for catalytic activities, a novel one-pot method for the detection of glucose was developed by the coupled catalytic reaction using GOx, Au@Ag heterogeneous NRs, and ABTS at nearly neutral pH ( $\mathrm{pH} 6.5)$ and $37^{\circ} \mathrm{C}$. This proposed method had simple and rapid processes, wide linear range $(0.05-20 \mathrm{mM})$, and reliability for the successful analysis of real samples. On the basis of these attractive and unique characteristics, Au@Ag heterogeneous NRs can become promising substitutes for peroxidase in analytical chemistry and environmental science.

KEYWORDS: Au@Ag heterogeneous nanorods, bimetallic catalysts, peroxidase mimetics, nearly neutral pH, spectrophotometric detection of glucose

\section{INTRODUCTION}

Hydrogen peroxide $\left(\mathrm{H}_{2} \mathrm{O}_{2}\right)$ is of great importance in many fields such as pharmaceutical assay, clinical diagnosis, bioanalysis, and food safety where detecting conditions are generally neutral $\mathrm{pH}^{1,2}$ Meanwhile, $\mathrm{H}_{2} \mathrm{O}_{2}$ is a usual side product of many enzymatic reactions, which are conducted in neutral condition., Therefore, it is of practical significance to study the detection of $\mathrm{H}_{2} \mathrm{O}_{2}$ or catalytic reaction in nearly neutral conditions. So far, lots of methods have been developed to detect $\mathrm{H}_{2} \mathrm{O}_{2}$, including titrimetry, ${ }^{5}$ spectrophotometry, ${ }^{6}$ fluorometry, ${ }^{7}$ electroanalysis, ${ }^{8}$ and chromatography, ${ }^{9}$ most of which are based on natural enzymes (especially peroxidase). ${ }^{10,11}$

Received: April 25, 2015

Accepted: June 15, 2015

Published: June 15, 2015 
Natural peroxidases, mainly including horseradish peroxidase (HRP) and seed coat soybean peroxidase (SBP), are of great practical significance in the fields of medicine, chemical industry, and food production. ${ }^{12,13}$ However, natural peroxidases as proteins suffer some disadvantages such as easily being denatured in complex conditions, being digested by proteases, being expensive, and being difficult to prepare and purify. ${ }^{14-17}$ Therefore, it is necessary to search for low-cost peroxidase mimetics with good stability to overcome these drawbacks of natural enzymes.

Recently, many efforts have been made to successfully develop nanomaterials as the efficient peroxidase alternatives, due to their unique properties such as high stability, low cost, large surface-tovolume ratio, enhanced mass transport, and high catalytic activity. ${ }^{15,18}$ For example, Wei and co-workers have reported that $\mathrm{Fe}_{3} \mathrm{O}_{4}$ magnetic nanoparticles (MNPs) as peroxidase mimetics for the detection of $\mathrm{H}_{2} \mathrm{O}_{2}$ and glucose in acidic conditions $(\mathrm{pH}$ $4.0){ }^{19}$ Yun et al. have successfully synthesized positively charged gold nanoparticles (NPs) as peroxidase mimetics for applications in $\mathrm{H}_{2} \mathrm{O}_{2}$ and glucose detection in $\mathrm{pH} 4.0$ buffer. ${ }^{20}$ These nanomaterial-based enzyme mimetics, which are defined as "nanozymes", would become the next-generation artificial enzymes. ${ }^{18}$ However, most of the reported peroxidase mimetics need to work in acidic conditions $(\mathrm{pH}<5.0)$ rather than nearly neutral conditions ( $\mathrm{pH} 5.0-7.4)$, such as graphene oxide $(\mathrm{pH}$ $4.0){ }^{11}$ carbon nanodots ( $\left.\mathrm{pH} 3.5\right),{ }^{21}$ gold NPs ( $\left.\mathrm{pH} 4.0\right),{ }^{20}$ silver NPs ( $\mathrm{pH} 4.0),{ }^{22} \mathrm{Fe}_{3} \mathrm{O}_{4} \mathrm{MNPs}(\mathrm{pH} 4.5),{ }^{23} \mathrm{~V}_{2} \mathrm{O}_{5}$ nanowires $(\mathrm{pH}$ $4.0)$, ${ }^{24} \mathrm{~V}_{2} \mathrm{O}_{3}$-ordered mesoporous carbon composites ( $\mathrm{pH}$ 4.0), ${ }^{25}$ and bull serum albumin templated $\mathrm{MnO}_{2} \mathrm{NPs}(\mathrm{pH}$ $4.0),{ }^{26}$ which would limit their practical applications. ${ }^{27}$ To date, there have been few reports that peroxidase mimetics could work in nearly neutral conditions. ${ }^{28-31}$

To overcome the above-mentioned limitation, we were supposed to improve the peroxidase mimetics in order to make it have optimal activity in nearly neutral conditions ( $\mathrm{pH}$ 6.07.4). It has been reported that some factors had influence on the catalytic activities of the enzyme mimetics. First, the activities of enzyme mimetics were tuned by controlling their sizes. ${ }^{32-36}$ Second, surface coating and modification can not only enhance the stability of the materials but also change surface properties and sequentially strengthen the catalytic activity. ${ }^{37-42}$ Meanwhile, this also depends on the charge characteristic of the reaction substrate. For example, Gao et al. have found that $\mathrm{Fe}_{3} \mathrm{O}_{4}$ MNPs wrapped by dextran had the highest peroxidase-like activity than $\mathrm{Fe}_{3} \mathrm{O}_{4}$ MNPs functionalized with 3-aminopropyltriethoxysilane or polyethylene glycol. ${ }^{43}$ In addition, Prussianblue coating could enhance the catalytic activity of the $\gamma-\mathrm{Fe}_{2} \mathrm{O}_{3}$ MNPs. ${ }^{44,45}$ Liu and co-workers researched the peroxidase-like activity of the Au@Pt nanorods (NRs) modified by polyelectrolytes, either negatively charged poly(sodium 4-styrenesulfonate) (PSS) or positively charged poly(diallyldimethylammoniumchioride) (PDDA). For the substrate of $3,3^{\prime}, 5,5^{\prime}$-tetramethylbenzidine (TMB), the negatively charged $\mathrm{Au} @$ Pt NRs yielded a higher affinity to TMB, while the positively charged NRs exhibited a relatively lower affinity. For 2,2' -azinobis(3-ethylbenzthiazoline-6-sulfonic acid) diammonium salt (ABTS), the opposite trend was observed. ${ }^{46} \mathrm{Yu}$ et al. compared the properties of iron-oxide NPs with different coatings and their interaction with different substrates of TMB and ABTS. ABTS, containing negatively charged sulfonic groups, gave it a strong electrostatic affinity toward positively charged NPs. Such an enhanced affinity results in a significantly improved peroxidase activity. Conversely, TMB, containing two amine groups, yields a strong affinity toward negatively charged NPs. ${ }^{47}$ Fan and coworkers reported that chitosan-coating increased the zeta potential of the $\mathrm{CoFe}_{2} \mathrm{O}_{4} \mathrm{NPs}$ (from $+6.6 \mathrm{mV}$ to $+45.8 \mathrm{mV}$ ), leading to the increase of affinity by enhancing the electrostatic interaction between the substrate and the complex surface, and the increase of peroxidase-like activity. ${ }^{48}$ Third, the composition of hybrid can change the catalytic activity by alloying or doping approaches. For instance, for $\mathrm{AgM}(\mathrm{M}=\mathrm{Au}, \mathrm{Pb}, \mathrm{Pt})$ bimetallic alloy-based peroxidase nanoenzymes, their catalytic activity could be fine-tuned by gradually changing the ratio of two metals except for size and shape. The composition-dependent activity resulted from the variation in electronic structure due to alloying and unstable alloys due to higher $\mathrm{Ag} / \mathrm{M}$ ratios. ${ }^{33} \mathrm{Au}-$ $\mathrm{Fe}_{3} \mathrm{O}_{4}$ could enhance the catalytic activity of $\mathrm{Fe}_{3} \mathrm{O}_{4}$ due to the polarization effect of $\mathrm{Au}$ on $\mathrm{Fe}_{3} \mathrm{O}_{4}{ }^{49} \mathrm{An} \mathrm{Fe}_{3} \mathrm{O}_{4}-\mathrm{Ag}$ hybrid submicrosphere was also developed as peroxidase mimetics and proven to have enhanced electrocatalytic activity toward $\mathrm{H}_{2} \mathrm{O}_{2}$ compared with only $\mathrm{Fe}_{3} \mathrm{O}_{4}$ modified electrode due to the combination of $\mathrm{Fe}_{3} \mathrm{O}_{4}$ and small amounts of Ag. ${ }^{50}$ Tao et al. reported that graphene oxide (GO) could regulate the peroxidase-like activity of gold nanoclusters (AuNCs) and that the GO-AuNCs hybrid exhibited high catalytic activity at neutral $\mathrm{pH} .^{29}$ Finally, the catalytic activities of the enzyme mimetics, containing metals, metal oxides and metal sulfide, could be changed under different $\mathrm{pH}$ conditions. ${ }^{19,37,43,51}$

The bimetallic Au@Ag heterogeneous NRs can be synthesized by large scale, ${ }^{52}$ which could be assembled with phage fusion protein to form a bionanostructure for targeted tumor optical detection and photothermal therapy. ${ }^{53}$ In this work, the Au@Ag heterogeneous NRs are reported as interesting peroxidase mimetics at nearly neutral $\mathrm{pH}$ conditions. Thus, the bimetallic peroxidase mimetics can be applied to detect $\mathrm{H}_{2} \mathrm{O}_{2}$ spectrophotometrically and accordingly to assay glucose in one-pot by coupled catalytic reaction using glucose oxidase $(\mathrm{GOx})$ in a $\mathrm{pH}$ 6.5 buffer solution.

\section{MATERIALS AND METHODS}

2.1. Chemicals and Materials. Hydrogen peroxide $\left(\mathrm{H}_{2} \mathrm{O}_{2}, 30 \%\right)$, chlorauric acid $\left(\mathrm{HAuCl}_{4} \cdot 3 \mathrm{H}_{2} \mathrm{O}\right)$, and silver nitrate $\left(\mathrm{AgNO}_{3}\right)$ were purchased from Sinopharm Chemical Reagent Co. ABTS, PDDA ( $\mathrm{Mw}$ 100,000-200,000), ethylene glycol (EG), and GOx were purchased from Sigma-Aldrich. TMB was purchased from TCI (Shanghai) Development Co., Ltd. Ultrapure water $(18 \mathrm{M} \Omega \mathrm{cm})$ was prepared using a Millipore Milli-Q system and used throughout. All other reagents were of the highest grade, and all solutions were prepared with ultrapure water.

2.2. Synthesis of Au@Ag Heterogeneous NRs. Au@Ag heterogeneous NRs were synthesized by coreduction of gold and silver sources in an EG solution through a straightforward polyol route, which was first reported in our previous work. ${ }^{52} \mathrm{Au} @ \mathrm{Ag}$ heterogeneous NRs with various aspect ratios can be prepared. Briefly, $\mathrm{HAuCl}_{4}(0.0175$ $\mathrm{mmol}), \mathrm{PDDA}$ (1.75 mmol), and varying amounts of $\mathrm{AgNO}_{3}(0.105$, 0.14 , and $0.21 \mathrm{mmol}$ ) aqueous solution were added to an EG solution $(70 \mathrm{~mL})$ in a brown glass vial under vigorous stirring, followed by incubation of the mixture at $195{ }^{\circ} \mathrm{C}$ for $72 \mathrm{~h}$. Finally, the glass vial was taken out from an oil bath and naturally cooled to room temperature. The Au@Ag heterogeneous NRs were collected by centrifugation and repeated washing.

2.3. Synthesis of Octahedral Au NPs and Cubical Silver NPs. The synthetic processes for octahedral Au NPs and cubical Ag NPs are similar to that of $\mathrm{Au} @ \mathrm{Ag}$ heterogeneous NRs except that only a given amount of single metal salt $\left(\mathrm{HAuCl}_{4}\right.$ or $\left.\mathrm{AgNO}_{3}\right)$ was introduced into an EG solution containing PDDA with a concentration of $25 \mathrm{mM}^{52,54}$ For example, the cubical Ag NP colloid was synthesized by heating the silver precursor containing of $1 \mathrm{mM} \mathrm{AgNO}_{3}$ and $25 \mathrm{mM}$ PDDA at $195^{\circ} \mathrm{C}$ for 


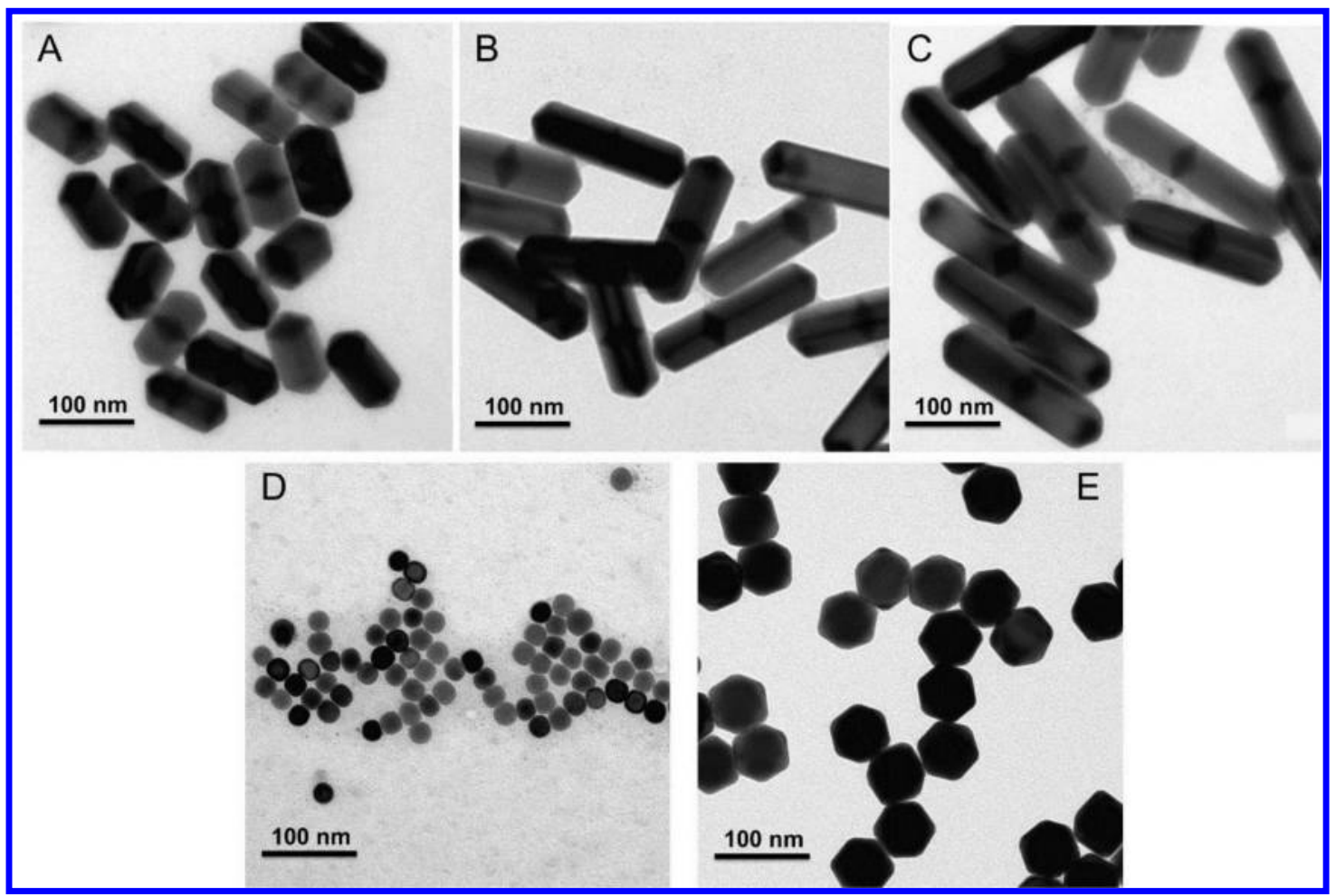

Figure 1. TEM images of Au@Ag heterogeneous NRs (A, B, and C) and NPs (D and E) with varying reaction molar ratios of Ag to Au. A, 6:1; B, 8:1; C, $12: 1 ; \mathrm{D}, 1: 0$; and E, 0:1.

$24 \mathrm{~h}$. We facilely harvested octahedral Au NPs when the gold precursor with $0.5 \mathrm{mM} \mathrm{AuCl}_{4}{ }^{-}$ions was reacted at $195{ }^{\circ} \mathrm{C}$ for $30 \mathrm{~min}$.

2.4. Catalytic Reaction Using Au@Ag Heterogeneous NRs as Peroxidase Mimetics. To investigate the catalytic activity of the Au@ Ag heterogeneous NRs toward $\mathrm{H}_{2} \mathrm{O}_{2}$, ABTS was chosen as the substrate, which can be oxidized by $\mathrm{H}_{2} \mathrm{O}_{2}$ to a colored product in the catalysis of the peroxidase mimetics (eq 1$).{ }^{19}$ In a typical experiment, the reaction system $(200 \mu \mathrm{L})$ contained $\mathrm{Au} @ \mathrm{Ag}$ heterogeneous NRs $(5 \mu \mathrm{g}), \mathrm{H}_{2} \mathrm{O}_{2}$ $(5 \mathrm{mM})$, and ABTS $(3 \mathrm{mM})$ in $20 \mathrm{mM}$ phosphate buffer $(\mathrm{PB}, \mathrm{pH} 6.5)$ at $25{ }^{\circ} \mathrm{C} . \mathrm{H}_{2} \mathrm{O}_{2}$ was finally added to initiate the reaction, and the absorbance at $414 \mathrm{~nm}$ was continuously measured for $10 \mathrm{~min}$. The Au@ $\mathrm{Ag}$ heterogeneous NRs (reaction molar ratio of $\mathrm{Ag}$ to $\mathrm{Au}$ of 12:1, aspect ratio of 3.7) were used throughout except when otherwise specified.

$$
\mathrm{H}_{2} \mathrm{O}_{2}+\mathrm{ABTS} \rightarrow \mathrm{H}_{2} \mathrm{O}+\text { oxidized ABTS }
$$

The influence of $\mathrm{pH}$ on the catalytic activity of the $\mathrm{Au} @ \mathrm{Ag}$ heterogeneous NRs was investigated by using different buffers $(20 \mathrm{mM}$, $\mathrm{pH} 1.0-12.0)$ : glycine- $\mathrm{HCl}$ buffer $(\mathrm{pH} 1.0-2.0)$, acetate buffer $(\mathrm{pH}$

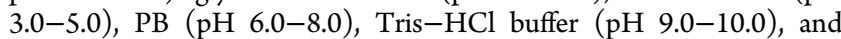
$\mathrm{NaHCO}_{3}-\mathrm{NaOH}$ buffer ( $\left.\mathrm{pH} 11.0-12.0\right)$. The influence of temperature on the catalytic activity of the $\mathrm{Au} @ \mathrm{Ag}$ heterogeneous NRs was also studied by performing the above reaction at different temperatures (4$\left.90^{\circ} \mathrm{C}\right)$. To examine the influence of temperature on the stability of $\mathrm{Au} @$ Ag heterogeneous NRs, they were incubated in PB solution $(20 \mathrm{mM}, \mathrm{pH}$ 6.5) at different temperatures from 4 to $100{ }^{\circ} \mathrm{C}$ for $2 \mathrm{~h}$. After that, the solutions were cooled on ice, and then the remaining relative activities were determined by the above assay. The maximum activity in each group of experiments was defined as $100 \%$ of relative activity.

To detect concentrations of $\mathrm{H}_{2} \mathrm{O}_{2}$, the Au@Ag heterogeneous NRs catalytic reactions were carried out using fixed concentration of ABTS (3 $\mathrm{mM})$ and varied concentrations of $\mathrm{H}_{2} \mathrm{O}_{2}(0-20 \mathrm{mM})$ as the substrate in $\mathrm{PB}$ solution $(20 \mathrm{mM}, \mathrm{pH}$ 6.5). After incubating for $10 \mathrm{~min}$, the absorbance spectra were recorded from 370 to $550 \mathrm{~nm}$.

2.5. Detection of Glucose Using GOx and Au@Ag Heterogeneous NRs. The detection of glucose was conducted by a one-pot method using GOx and Au@Ag heterogeneous NRs. The coupled reactions were carried out in $200 \mu \mathrm{L}$ of $\mathrm{PB}$ solution $(20 \mathrm{mM}, \mathrm{pH} 6.5)$ containing the varying concentrations of glucose $(0-30 \mathrm{mM})$, ABTS (3
$\mathrm{mM})$, GOx (2 mg/mL), and Au@Ag heterogeneous NRs $(5 \mu \mathrm{g})$ at 37 ${ }^{\circ} \mathrm{C}$ for $30 \mathrm{~min}$, and then the absorbances at $414 \mathrm{~nm}$ were measured. The limit of detection (LOD) is calculated by using the typical formula: LOD $=3 \sigma / S$, where $\sigma$ is standard deviation of the blank, and $S$ is the slope of the calibration curve. ${ }^{55}$

2.6. Instrumentation. The images of the Au@Ag heterogeneous NRs or NPs were were characterized by transmission electron microscopy (TEM, JEM-1400, Japan). Samples for TEM examination were prepared by putting a droplet of the treated solution on a copper grid coated with a thin carbon film and evaporating in air at room temperature. The absorption spectra and colorimetric detection at 414 $\mathrm{nm}$ were performed with a spectrophotometer with a BioTek Synergy HT SIAFRTD microplate reader (BioTek Instruments Inc., Winooski, USA). Zeta potential $(\zeta)$ was detected by a BI-EKA potential analyzer (Brookhaven Instruments Corp., Brookhaven, USA).

\section{RESULTS AND DISCUSSION}

\subsection{Synthesis and Morphology Characterization of} Au@Ag Heterogeneous NRs. By a facile one-pot polyol process, Au@Ag heterogeneous NRs were obtained, using polyelectrolyte PDDA as both the shape-controller and stabilizer. TEM images demonstrate that the product was dominated by uniform Au@Ag heterogeneous NRs, in which a single dark object $(\mathrm{Au})$ embedded in the body of each rod $(\mathrm{Ag})$ was clearly observed (Figure $1 \mathrm{~A}-\mathrm{C}$ ). Interestingly, the length of the harvested NRs was gradually increased with increasing the addition amount of $\mathrm{AgNO}_{3}$ from 0.105 to $0.21 \mathrm{mmol}$, but their width was almost unchanged, thus resulting in the increase in the aspect ratio of Au@Ag heterogeneous NRs. For example, the width of Au@Ag heterogeneous NRs was $55 \pm 4 \mathrm{~nm}$, and the corresponding lengths of Au@Ag heterogeneous NRs were 100 $\pm 6 \mathrm{~nm}, 163 \pm 12 \mathrm{~nm}$, and $205 \pm 23 \mathrm{~nm}$, respectively (Figure $1 \mathrm{~A}-\mathrm{C})$. The possible growth process of the Au@Ag heterogeneous NRs is shown in Figure S1 (Supporting Information), where $\mathrm{Au}$ could provide the deposition surface 
for the growth of Ag. Two end facets of NRs were the active sites for $\mathrm{Ag}$ growth where $\mathrm{Ag}$ atoms were directionally deposited, whereas the lateral deposition of $\mathrm{Ag}$ atoms was blocked. ${ }^{52}$ However, the UV-vis-NIR absorption spectrum of the Au@Ag heterogeneous NRs (with the molar ratio of $\mathrm{Ag}$ to $\mathrm{Au}$ of 12:1in the reaction solution) showed two strong absorption peaks at 401 and $770 \mathrm{~nm}$ (curve a in Figure S2, Supporting Information), which was respectively originated from the transverse and longitudinal localized surface plasmon resonances. Futhermore, as the aspect ratio increased from 1.8 to 3.7 , the longitudinal absorption peak was systematically red-shifted from 540 to 770 $\mathrm{nm}$ (Figure S2, Supporting Information). Similarly, yellow cubical Ag NPs with the average size of $24 \pm 3 \mathrm{~nm}$ (Figure 1D) and octahedral Au NPs with an edge size of $64 \pm 7 \mathrm{~nm}$ (Figure $1 \mathrm{E})$ were prepared by introducing only $0.5 \mathrm{mM} \mathrm{HAuCl}_{4}$ or $1 \mathrm{mM}$ $\mathrm{AgNO}_{3}$ into an EG solution containing $25 \mathrm{mM}$ PDDA. The asprepared $\mathrm{Au}$ NPs and Ag NPs were stabilized by PDDA.

In this context, by using $\mathrm{Au} \mathrm{NRs}$ as seeds in $\mathrm{AgNO}_{3}$-containing cetyltrimethylammonium bromide (CTAB) aqueous solution, a multistep seed-mediated growth procedure was reported to synthesizeAu@Ag core-shell NRs. ${ }^{56}$ The length of the resultant $\mathrm{Au} @ \mathrm{Ag}$ core-shell NRs was highly dependent on that of the seeds of Au NRs. As such, the aspect ratio of Au@Ag core-shell NRs was decreased as the Ag shell increased, which gave rise to the blue-shift of the longitudinal absorption peak. ${ }^{56}$ In our case, the Au was totally buried in Ag to emerge with a clear boundary between $\mathrm{Ag}$ and $\mathrm{Au}$ (Figure $1 \mathrm{~A}-\mathrm{C}$ ), forming the $\mathrm{Au} @ \mathrm{Ag}$ heterogeneous NRs rather than Au@Ag alloy or core-shell NRs. Additionally, the main composition of Au@Ag heterogeneous $\mathrm{NRs}$ is $\mathrm{Ag}(>85 \%)$ because the molar ratio of $\mathrm{Ag}$ to $\mathrm{Au}$ in the reaction solution is not lower than 6:1. However, the $\mathrm{Ag}$ content in the Au@Ag core-shell NRs generally accounted for less than 60\%. ${ }^{57,58}$ Moreover, our Au@Ag heterogeneous NRs showed excellent stability, which enabled us to retain their morphology and properties. ${ }^{53,59}$ Therefore, compared with the traditional multistep seed-mediated methods of Au@Ag core-shell NRs, ${ }^{57,58,60}$ our one-pot route to synthesize Au@Ag heterogeneous NRs is superior because of its simplicity, cost-effectiveness, controllability, and large-scale production.

3.2. Characterizing the Peroxidase-Like Activity of Au@Ag Heterogeneous NRs. To investigate the peroxidaselike activity of $\mathrm{Au} @ \mathrm{Ag}$ heterogeneous NRs, the experiments were carried out spectrophotometrically using ABTS and $\mathrm{H}_{2} \mathrm{O}_{2}$ as the substrate (Scheme 1). The reaction mixture with $\mathrm{Au} @ \mathrm{Ag}$

Scheme 1. Au@Ag Heterogeneous NR-Catalyzed Reaction of ABTS with $\mathrm{H}_{2} \mathrm{O}_{2}$

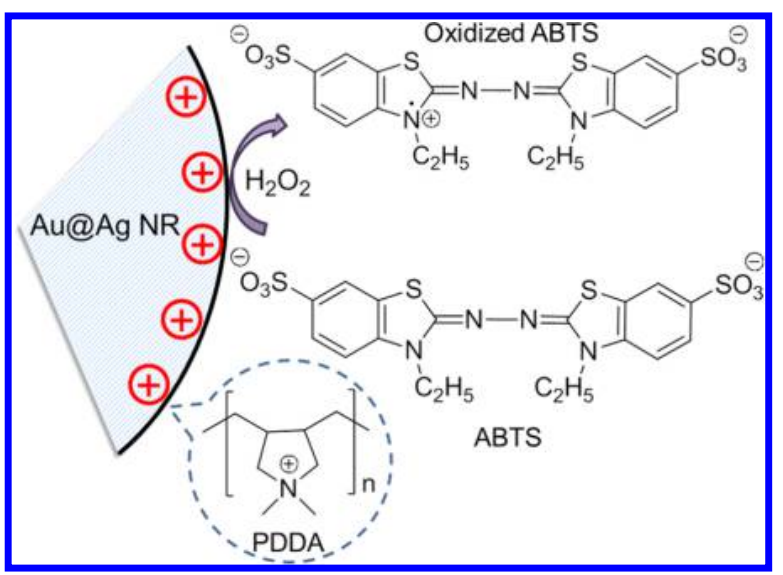

heterogeneous NRs became green (inset a, Figure 2), which showed the maximum optical absorption peak at $414 \mathrm{~nm}$ (curve

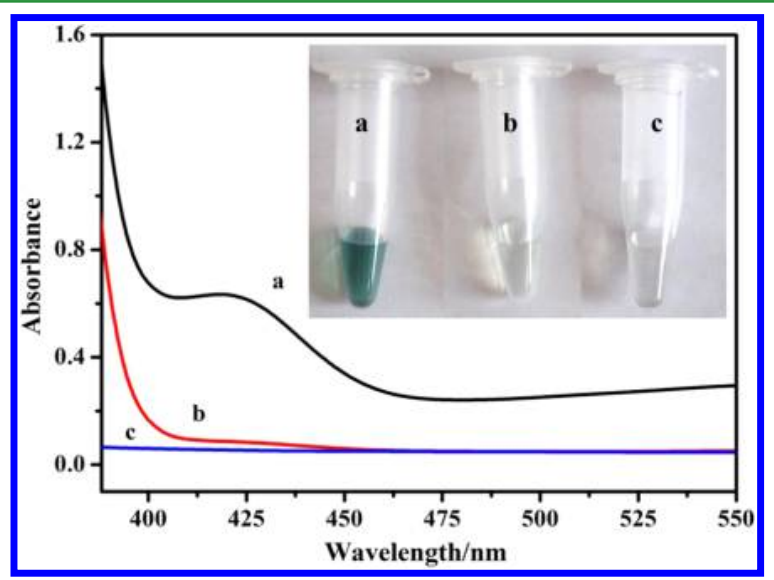

Figure 2. Optical absorption spectra of different systems in PB solution ( $\mathrm{pH}$ 6.5) in the presence of $3 \mathrm{mM} \mathrm{ABTS}$ and $5 \mathrm{mM} \mathrm{H}_{2} \mathrm{O}_{2}$ with (a) and without (b) Au@Ag heterogeneous NRs and the absorbance spectrum of Au@Ag heterogeneous NRs (c). Inset, photographs of reaction solutions related to three curves $(a-c)$.

a, Figure 2), while there were negligible absorbances in the reaction mixture without Au@Ag heterogeneous NRs (curve b, Figure 2) and $\mathrm{Au} @ A g$ heterogeneous NRs only in the absence of ABTS and $\mathrm{H}_{2} \mathrm{O}_{2}$ (curve c, Figure 2). These results implied that $\mathrm{Au} @ \mathrm{Ag}$ heterogeneous NRs had the catalytic activity of the oxidation of ABTS by $\mathrm{H}_{2} \mathrm{O}_{2}$ and could be used as a peroxidase mimetic to detect $\mathrm{H}_{2} \mathrm{O}_{2}$ in the presence of ABTS by monitoring the absorbance at $414 \mathrm{~nm}$.

The effect of $\mathrm{pH}$ on the peroxidase-like activity of the Au@Ag heterogeneous NRs was investigated by varying buffer $\mathrm{pH}$ from 1 to 12 , while the $\mathrm{Au} @ \mathrm{Ag}$ heterogeneous NRs, ABTS, and $\mathrm{H}_{2} \mathrm{O}_{2}$ were kept at the same concentrations. Like that of other peroxidase mimetics, the activity of NRs was also dependent on $\mathrm{pH}$ (Figure 3). Interestingly, Au@Ag heterogeneous NRs exhibited high activity ( $>94 \%$ maximum activity) over a wide $\mathrm{pH}$ range ( $\mathrm{pH} 4.0-6.5)$. Even at $\mathrm{pH} 7.0$, the NRs remained about $70 \%$ relatively active. Therefore, the Au@Ag heterogeneous NRs showed high catalytic activity at nearly neutral $\mathrm{pH}$ conditions,

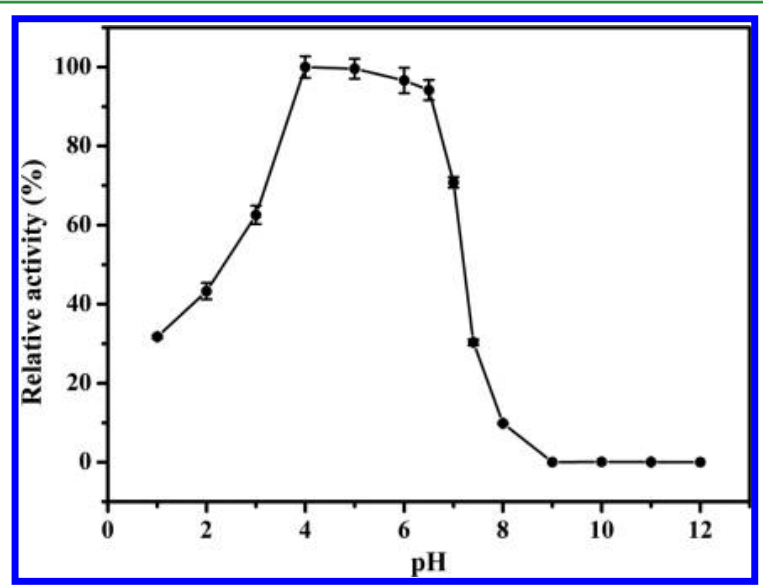

Figure 3. pH-dependent activity of $\mathrm{Au} @ \mathrm{Ag}$ heterogeneous NRs in a system containing $3 \mathrm{mM} \mathrm{ABTS}$ and $5 \mathrm{mM} \mathrm{H}_{2} \mathrm{O}_{2}$ in different buffers $(\mathrm{pH}$ $1.0-12.0)$ at $414 \mathrm{~nm}$. The highest point was defined as $100 \%$ relative activity. 
which is a unique feature among most of peroxidase mimetics and similar to natural peroxidases. ${ }^{61,62}$ However, as the $\mathrm{pH}$ was above 7.0, the absorbance decreased remarkably due to the inhibition of the catalytic activity ${ }^{40}$ and instability of $\mathrm{H}_{2} \mathrm{O}_{2}$ in alkaline solution. ${ }^{30,63}$ The results also indicated that the $\mathrm{pH}$ dependent activity was related to not only the substrates but also catalysts themselves.

The effect of temperature on the peroxidase-like activity of the $\mathrm{Au} @ \mathrm{Ag}$ heterogeneous NRs was studied by varying the temperature from 4 to $90{ }^{\circ} \mathrm{C}$, while the $\mathrm{Au} @ \mathrm{Ag}$ heterogeneous $\mathrm{NRs}, \mathrm{ABTS}$, and $\mathrm{H}_{2} \mathrm{O}_{2}$ were kept at constant concentrations. The temperature-dependent activity curve is shown in Figure S3 (Supporting Information). The Au@Ag heterogeneous NRs exhibited optimal peroxidase-like activity, which was stable within $20-40{ }^{\circ} \mathrm{C}$. However, the absorbance decreased obviously when the temperature would continue to rise.

The stability of the Au@Ag heterogeneous NRs was investigated at $\mathrm{pH} 6.5$ with varying temperature from 4 to 90 ${ }^{\circ} \mathrm{C}$ (Figure S4, Supporting Information). The NRs retained nearly full catalytic activity after incubation at $40^{\circ} \mathrm{C}$ for $2 \mathrm{~h}$. With the increase of the temperature from 40 to $100{ }^{\circ} \mathrm{C}$, the activity declined slightly; however, about $75 \%$ of the original activity still remained even at $100{ }^{\circ} \mathrm{C}$, indicating that the $\mathrm{Au} @ \mathrm{Ag}$ heterogeneous NRs were very stable over the wide temperature range. Moreover, the peroxidase-like activity of the $\mathrm{Au} @ \mathrm{Ag}$ heterogeneous NRs had no obvious reduction after long-term storage, suggesting that it could be used for practical applications.

3.3. Effect of the Nano-structure on the PeroxidaseLike Activity of Au@Ag Heterogeneous NRs. To study the effect of the nanostructure on peroxidase-like activity, we synthesized PDDA-stabilized Au@Ag heterogeneous NRs with different molar ratios of Ag to $\mathrm{Au}$ (12:1, 8:1, and 6:1), which had different aspect ratios of 3.7, 3.0, and 1.8, respectively (Figure 1). Their peroxidase-like activities were continuously detected at $\mathrm{pH}$ 6.5 for $10 \mathrm{~min}$. As shown in Figure 4, the higher aspect ratio of NRs showed higher catalysis activity, while there was no observable activity for both PDDA-stabilized Au NPs and Ag

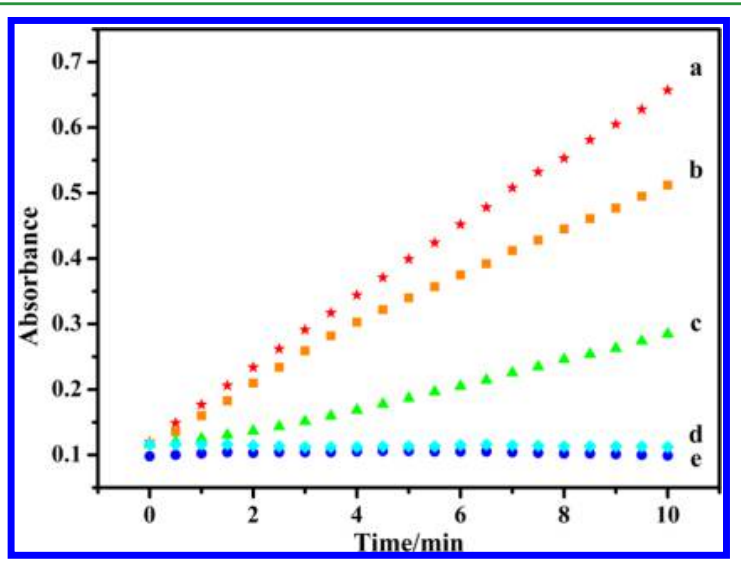

Figure 4. Absorbance curves of an ABTS oxidation system as a function of time for different nanomaterials. The absorbance at $414 \mathrm{~nm}$ was measured in PB solution ( $\mathrm{pH}$ 6.5) containing $3 \mathrm{mM}$ ABTS and $5 \mathrm{mM}$ $\mathrm{H}_{2} \mathrm{O}_{2}$ in the presence of different nanomaterials: (a) PDDA-stabilized $\mathrm{Au} @ \mathrm{Ag}$ heterogeneous NRs (reaction molar ratio of Ag/Au of 12:1; aspect ratio of 3.7); (b) PDDA-stabilized Au@Ag heterogeneous NRs (reaction molar ratio of Ag/Au of 8:1; aspect ratio of 3.0); (c) PDDAstabilized Au@Ag heterogeneous NRs (reaction molar ratio of Ag/Au of 6:1; aspect ratio of 1.8); (d), PDDA-stabilized Au NPs; and (e), PDDAstabilized Ag NPs.
NPs at $\mathrm{pH}$ 6.5, which is in agreement with a previous report. ${ }^{22}$ The exact reason why Au@Ag heterogeneous NRs exhibited this unique peroxidase-like activity is unclear for the moment. These results may be ascribed to the following reasons. First, the surface of Au@Ag heterogeneous NRs is positively charged due to the coverage with polycationic PDDA, which could provide a strong electrostatic affinity toward the negatively charged ABTScontaining sulfonic groups. ${ }^{47}$ According to potential analysis results, the zeta potential of $\mathrm{NRs}$ was $+45 \mathrm{mV}$ at $\mathrm{pH}$ 6.5. This could not only enhance the dispersity of NRs but also increase the affinity of NRs to ABTS at nearly neutral $\mathrm{pH}$, which may improve the activity of NRs (Figure 3). In support of this point, we checked the peroxidase-like activity of Au@Ag heterogeneous NRs using positively charged TMB as substrate at $\mathrm{pH} 6.5$ with other conditions kept the same. Interestingly, observable peroxidase-like activity was not detected (data not shown), indicating that TMB could not adsorb onto $\mathrm{Au} @ \mathrm{Ag}$ heterogeneous NRs, due to the repulsive interaction between the positively charged catalyst surface and positively charged TMB. Second, it was reported that the catalytic activity could be improved by increasing the $\mathrm{Ag} / \mathrm{Au}$ molar ratio, considering that the $\mathrm{Ag} / \mathrm{M}(\mathrm{M}=$ metal $)$ alloy with higher $\mathrm{Ag}$ ratio was unstable enough in the presence of $\mathrm{H}_{2} \mathrm{O}_{2}$ and promoted the reduction of $\mathrm{H}_{2} \mathrm{O}_{2},{ }^{33}$ which is consistent with our result (Figure 4, curves ac). Surprisingly, Ag NPs alone almost did not exhibit any catalytic activity at the nearly neutral $\mathrm{pH}$ (curve e, Figure 4), though they worked at $\mathrm{pH} 4$. Au NPs exhibited the same behavior (curve d, Figure 4). These results indicated that the observed activity of $\mathrm{Au} @ \mathrm{Ag}$ heterogeneous NRs could be attributed to the synergistic effect between $\mathrm{Au}$ and $\mathrm{Ag}$, considering that both $\mathrm{Au}^{64}$ and $\mathrm{Ag}^{22}$ have peroxidase activities and that either $\mathrm{Au}^{49}$ or $\mathrm{Ag}^{50}$ can enhance the catalytic activity of a heterogeneous nanozyme. A similar effect was also reported for GO-AuNCs. ${ }^{29,49}$ In addition, the variation in electronic structure due to alloying was believed to be partially responsible for the enhanced activity. ${ }^{33}$ The nanosized catalyst could also enhance the peroxidase-like catalytic activity. ${ }^{65}$ Taken together, due to the synergistic effect of specific surface property, composition, and nanostructure, the catalytic activity of $\mathrm{Au} @ \mathrm{Ag}$ heterogeneous NRs at $\mathrm{pH} 6.5$ differed from that of other similar nanomaterials, such as positively charged PDDA modified Au@Pt core/shell NRs (pH 4.5) or negatively charged PSS modified Au@Pt core/ shell NRs ( $\mathrm{pH} 4.5),{ }^{46}$ positively charged CTAB-modified Au@Pt core/shell NRs ( $\mathrm{pH} 4.5){ }^{40}$ 2-aminoethanethiol modified Au NPs, ${ }^{66}$ and chitosan-stabilized Ag NPs ( $\left.\mathrm{pH} 4.0\right) .^{22}$ This peroxidase-like catalytic activity at the nearly neutral $\mathrm{pH}$ was similar to GO-AuNCs ${ }^{29}$ and positively charged CTAB modified Ag@Au or Ag@Pt nanoboxes. ${ }^{67}$

3.4. Detection of $\mathrm{H}_{2} \mathrm{O}_{2}$ Using Au@Ag Heterogeneous NRs. At the nearly neutral $\mathrm{pH}(\mathrm{pH}$ 6.5), a spectrophotometric detection of $\mathrm{H}_{2} \mathrm{O}_{2}$ was carried out using the $\mathrm{Au} @ \mathrm{Ag}$ heterogeneous NRs as catalysts. Taking the convenience of operation into consideration, the experiments were performed at room temperature $\left(25^{\circ} \mathrm{C}\right)$. As shown in Figure 5, the absorbance of ABTS oxidation was dependent on $\mathrm{H}_{2} \mathrm{O}_{2}$ concentration. Further, the calibration curve was obtained by plotting the absorbance at $414 \mathrm{~nm}$ with varying $\mathrm{H}_{2} \mathrm{O}_{2}$ concentrations (inset, Figure 5). The linear part was over the concentration range from 0.01 to $10 \mathrm{mM}$ (regression equation: $y=0.1016 x+0.0003 ; R^{2}=$ $0.998)$ with a LOD of $6 \mu \mathrm{M}(\mathrm{S} / \mathrm{N}=3)$. Noteworthy, the $\mathrm{H}_{2} \mathrm{O}_{2}$ concentration was detected in neutral conditions, which was different from other peroxidase-mimetic materials used in acidic conditions reported so far. ${ }^{23,24,26}$ In addition, this performance 


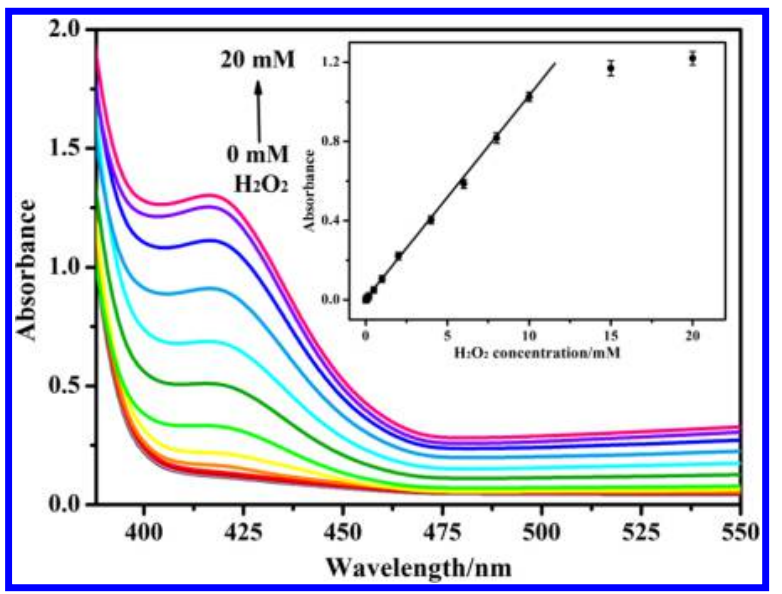

Figure 5. Optical absorption spectra of an ABTS oxidation system in the presence of Au@Ag NRs with different concentrations of $\mathrm{H}_{2} \mathrm{O}_{2}$ from 0 to $20 \mathrm{mM}$ at $25^{\circ} \mathrm{C}$ in $\mathrm{PB}$ solution ( $\mathrm{pH}$ 6.5). Inset, the absorbance at 414 $\mathrm{nm}$ as a function of $\mathrm{H}_{2} \mathrm{O}_{2}$ concentration.

can also be compared with our recent results on the detection of $\mathrm{H}_{2} \mathrm{O}_{2}$ by using $\mathrm{Au} @ \mathrm{Ag}$ heterogeneous NRs-based electrochemical sensors. ${ }^{59}$ Thus, it is beneficial to directly detect the real samples (such as serum and drink) without adjusting the $\mathrm{pH}$ value. Meanwhile, the Au@Ag heterogeneous NRs could be coupled with other enzymes in a one-pot catalytic reaction.

$$
\text { glucose }+\mathrm{O}_{2} \stackrel{\mathrm{GO}_{\mathrm{x}}}{\longrightarrow} \mathrm{H}_{2} \mathrm{O}_{2}+\text { gluconic acid }
$$

3.5. Detection of Glucose Using GOx and Au@Ag Heterogeneous NRs in One-Pot. Because Au@Ag heterogeneous NRs ( $\mathrm{pH} 4.0-6.5)$ and GOx $(\mathrm{pH} \mathrm{5.0-7.0)})^{68-70}$ have a similar optimal $\mathrm{pH}$ for catalytic activities, the formation of $\mathrm{H}_{2} \mathrm{O}_{2}$ catalyzed by $\mathrm{GOx}$ (eq 2) and reduction of $\mathrm{H}_{2} \mathrm{O}_{2}$ catalyzed by $\mathrm{Au} @ A g$ heterogeneous NRs (eq 1) could be applied in the same system. Therefore, we developed a one-pot method for the detection of glucose at nearly neutral $\mathrm{pH}$ ( $\mathrm{pH}$ 6.5) (Scheme 2). Because GOx exhibited optimal activity at about $37^{\circ} \mathrm{C},{ }^{3}$ which is within the optimal temperature of $20-40{ }^{\circ} \mathrm{C}$ for $\mathrm{Au} @ \mathrm{Ag}$ heterogeneous NRs, we chose $37^{\circ} \mathrm{C}$ as the reaction temperature for the one-pot method. The regression equation was $y=$ $0.03150 x+0.0031\left(R^{2}=0.998\right)$ with a LOD of $39 \mu \mathrm{M}(\mathrm{S} / \mathrm{N}=3)$.

Scheme 2. Glucose Detection Using GOx and Au@Ag Heterogeneous NRs in One-Pot at Nearly Neutral pH Conditions

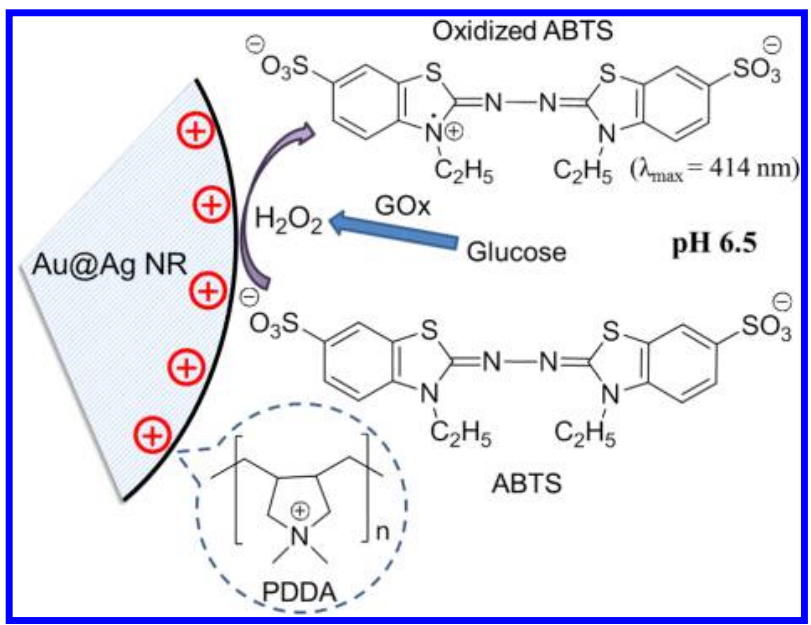

The linear range was $0.05-20 \mathrm{mM}$ (Figure 6), which was wider than $\mathrm{Fe}_{3} \mathrm{O}_{4}$ MNP (0.05-1 mM) ${ }^{36}$ and Au NP (0.018-1.1

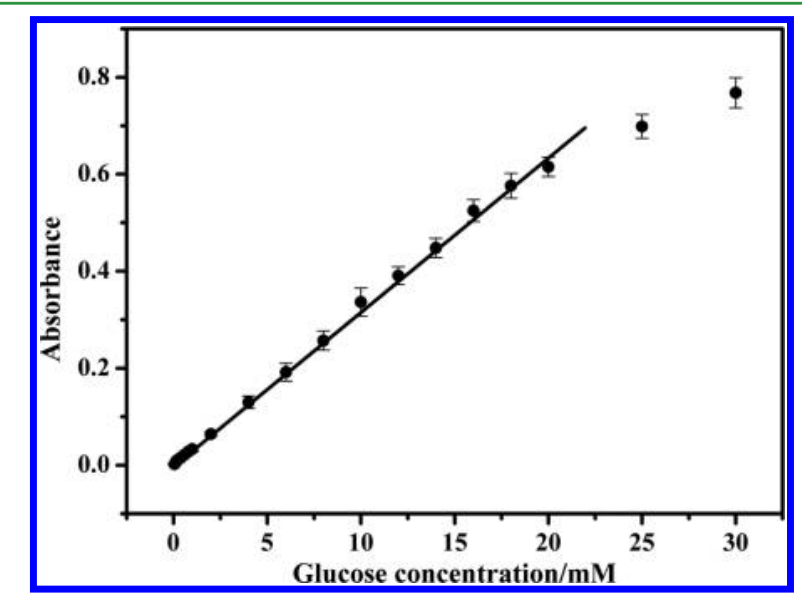

Figure 6. Calibration curve for glucose.

$\mathrm{mM})^{20}$-based colorimetric detection of glucose. It is worth noting that our proposed strategy excelled the general methods reported so far, ${ }^{19,47}$ which were conducted by two separated and coupled steps at quite different $\mathrm{pH}$ conditions (the formation of $\mathrm{H}_{2} \mathrm{O}_{2}$ catalyzed by GOx and reduction of $\mathrm{H}_{2} \mathrm{O}_{2}$ catalyzed by nanomaterials). The as-prepared Au@Ag heterogeneous NRs could completely substitute the natural peroxidases and adapt to the neutral $\mathrm{pH}$ conditions.

To investigate the specificity of this method, a control experiment was conducted using other sugars instead of glucose (Figure S5, Supporting Information). Because of the specificity of GOx, the method had no obvious responses to the control sugars and showed an excellent specificity toward the detection of glucose.

To confirm the practicability, the method was used in an analysis of real samples. The concentrations were calculated based on the calibration curve (Table S1, Supporting Information). The results by our method were in good agreement with the known results by general methods, and the relative errors were within $6.2 \%$. The relative standard deviation and recoveries were respectively within $5.2 \%$ and $98.0-101.4 \%$, demonstrating the excellent precision, accuracy, and reliability of the proposed method for practical applications.

\section{CONCLUSIONS}

In summary, we have demonstrated that the $\mathrm{Au} @ \mathrm{Ag}$ heterogeneous NRs could be used as unique and attractive peroxidase mimetics, which have high catalytic activity at nearly neutral $\mathrm{pH}$ and broad temperature range. Further, the Au@Ag heterogeneous NRs were used for the spectrophotometric detection of $\mathrm{H}_{2} \mathrm{O}_{2}$, and the analytical method exhibited a sensitive and reliable response to $\mathrm{H}_{2} \mathrm{O}_{2}$ at nearly neutral $\mathrm{pH}$. Because of the similar optimal $\mathrm{pH}$ for catalytic activities of $\mathrm{GOx}$ and Au@Ag heterogeneous NRs, we developed the one-pot method for the detection of glucose at $\mathrm{pH} 6.5$, which had a linear range of $0.05-20 \mathrm{mM}$ and a LOD of $25 \mu \mathrm{M}$ glucose. This method was simple and reliable for the analysis of real samples. Besides, the Au@Ag heterogeneous NRs as peroxidase mimetics were very stable at high temperature and long-term storage. Thus, the Au@Ag heterogeneous NRs are promising as peroxidase mimetics for potential application in analytical chemistry and environmental science. This work will provide a 
strategy to develop the catalytic activity of peroxidase mimetics by changing their composition and surface property and make a great influence on the next generation of enzyme mimetics system.

\section{ASSOCIATED CONTENT}

\section{S Supporting Information}

Schematic illustration of the growth of Au@Ag heterogeneous NRs; UV-vis-NIR absorption spectra of Au@Ag heterogeneous NRs and nanoparticles; temperature-dependent activity and temperature stability of the $\mathrm{Au} @ \mathrm{Ag}$ heterogeneous NRs; specificity of the proposed colorimetric glucose detection; and spectrophotometric detection of glucose in real samples using the proposed method. The Supporting Information is available free of charge on the ACS Publications website at DOI: 10.1021/ acsami.5b03591.

\section{AUTHOR INFORMATION}

\section{Corresponding Author}

*Tel: +86532 80662758. Fax: +86532 80662778. E-mail: liuah@qibebt.ac.cn.

\section{Author Contributions}

"L.H. and C.L. contributed equally to this work.

\section{Notes}

The authors declare no competing financial interest.

\section{ACKNOWLEDGMENTS}

This work was financially supported in part by National Natural Science Foundation of China (Nos. 91227116, 21275152, and 21475144)

\section{REFERENCES}

(1) Dodeigne, C.; Thunus, L.; Lejeune, R. Chemiluminescence as Diagnostic Tool. A Review. Talanta 2000, 51, 415-439.

(2) Engvall, E. Enzyme Immunoassay ELISA and EMIT. In Methods in Enzymology; Academic Press: New York, 1980; pp 419-439.

(3) Veitch, N. C. Horseradish Peroxidase: A Modern View of a Classic Enzyme. Phytochemistry 2004, 65, 249-259.

(4) Huggett, A. S. G.; Nixon, D. A. Use of Glucose Oxidase, Peroxidase, and $o$-Dianisidine in Determination of Blood and Urinary Glucose. Lancet 1957, 270, 368-370.

(5) Bodiroga, M.; Ognjanovic, J. Determination of Peracetic Acid and Hydrogen Peroxide in a Preparation. Vojnosanit. Pregl. 2002, 59, 277279.

(6) Chang, Q.; Tang, H. Optical Determination of Glucose and Hydrogen Peroxide Using a Nanocomposite Prepared from Glucose Oxidase and Magnetite Nanoparticles Immobilized on Graphene Oxide. Microchim. Acta 2014, 181, 527-534.

(7) Hirakawa, K. Fluorometry of Hydrogen Peroxide Using Oxidative Decomposition of Folic Acid. Anal. Bioanal. Chem. 2006, 386, 244-248.

(8) Yi, Q.; Niu, F.; Li, L.; Du, R.; Zhou, Z.; Liu, X. Novel Nanoporous Silver Particles for Electro-Reduction of Hydrogen Peroxide in Alkaline Media. J. Electroanal. Chem. 2011, 654, 60-65.

(9) Hong, J. G.; Maguhn, J.; Freitag, D.; Kettrup, A. Determination of $\mathrm{H}_{2} \mathrm{O}_{2}$ and Organic Peroxides by High-Performance Liquid Chromatography with Post-Column UV Irradiation, Derivatization and Fluorescence Detection. Fresenius J. Anal. Chem. 1998, 361, 124-128.

(10) Ruzgas, T.; Csöregi, E.; Emnéus, J.; Gorton, L.; Marko-Varga, G. Peroxidase-Modified Electrodes: Fundamentals and Application. Anal. Chim. Acta 1996, 330, 123-138.

(11) Song, Y.; Qu, K.; Zhao, C.; Ren, J.; Qu, X. Graphene Oxide: Intrinsic Peroxidase Catalytic Activity and Its Application to Glucose Detection. Adv. Mater. 2010, 22, 2206-2210.

(12) Burnette, F. S. Peroxidase and Its Relationship to Food Flavor and Quality: A Review. J. Food Sci. 1977, 42, 1-6.
(13) Koeller, K. M.; Wong, C.-H. Enzymes for Chemical Synthesis. Nature 2001, 409, 232-240.

(14) Breslow, R. Biomimetic Chemistry and Artificial Enzymes: Catalysis by Design. Acc. Chem. Res. 1995, 28, 146-153.

(15) Lin, Y.; Ren, J.; Qu, X. Catalytically Active Nanomaterials: A Promising Candidate for Artificial Enzymes. Acc. Chem. Res. 2014, 47, 1097-1105.

(16) Wulff, G. Enzyme-Like Catalysis by Molecularly Imprinted Polymers. Chem. Rev. 2001, 102, 1-28.

(17) Murakami, Y.; Kikuchi, J.-I.; Hisaeda, Y.; Hayashida, O. Artificial Enzymes. Chem. Rev. 1996, 96, 721-758.

(18) Wei, H.; Wang, E. Nanomaterials with Enzyme-Like Characteristics(Nanozymes): Next-Generation Artificial Enzymes. Chem. Soc. Rev. 2013, 42, 6060-6093.

(19) Wei, H.; Wang, E. $\mathrm{Fe}_{3} \mathrm{O}_{4}$ Magnetic Nanoparticles as Peroxidase Mimetics and Their Applications in $\mathrm{H}_{2} \mathrm{O}_{2}$ and Glucose Detection. Anal. Chem. 2008, 80, 2250-2254.

(20) Jv, Y.; Li, B.; Cao, R. Positively-Charged Gold Nanoparticles as Peroxidase Mimic and Their Application in Hydrogen Peroxide and Glucose Detection. Chem. Commun. 2010, 46, 8017-8019.

(21) Shi, W.; Wang, Q.; Long, Y.; Cheng, Z.; Chen, S.; Zheng, H.; Huang, Y. Carbon Nanodots as Peroxidase Mimetics and Their Applications to Glucose Detection. Chem. Commun. 2011, 47, 66956697.

(22) Jiang, H.; Chen, Z.; Cao, H.; Huang, Y. Peroxidase-Like Activity of Chitosan Stabilized Silver Nanoparticles for Visual and Colorimetric Detection of Glucose. Analyst 2012, 137, 5560-5564.

(23) Liang, M.; Fan, K.; Pan, Y.; Jiang, H.; Wang, F.; Yang, D.; Lu, D.; Feng, J.; Zhao, J.; Yang, L.; Yan, $\mathrm{X} . \mathrm{Fe}_{3} \mathrm{O}_{4}$ Magnetic Nanoparticle Peroxidase Mimetic-Based Colorimetric Assay for the Rapid Detection of Organophosphorus Pesticide and Nerve Agent. Anal. Chem. 2012, 85, 308-312.

(24) André, R.; Natálio, F.; Humanes, M.; Leppin, J.; Heinze, K.; Wever, R.; Schröder, H. C.; Müller, W. E. G.; Tremel, W. $\mathrm{V}_{2} \mathrm{O}_{5}$ Nanowires with an Intrinsic Peroxidase-Like Activity. Adv. Funct. Mater. 2011, 21, 501-509.

(25) Han, L.; Zeng, L.; Wei, M.; Li, C.; Liu, A. $\mathrm{V}_{2} \mathrm{O}_{3}$-Ordered Mesoporous Carbon Composite with Novel Peroxidase-Like Activity towards Glucose Colorimetric Assay. Nanoscale 2015, DOI: 10.1039/ C5NR02694F.

(26) Liu, X.; Wang, Q.; Zhao, H.; Zhang, L.; Su, Y.; Lv, Y. BSATemplated $\mathrm{MnO}_{2}$ Nanoparticles as both Peroxidase and Oxidase Mimics. Analyst 2012, 137, 4552-4558.

(27) Lin, Y.; Ren, J.; Qu, X. Nano-Gold as Artificial Enzymes: Hidden Talents. Adv. Mater. 2014, 26, 4200-4217.

(28) Dai, Z.; Liu, S.; Bao, J.; Ju, H. Nanostructured FeS as a Mimic Peroxidase for Biocatalysis and Biosensing. Chem.-Eur. J. 2009, 15, 4321-4326.

(29) Tao, Y.; Lin, Y.; Huang, Z.; Ren, J.; Qu, X. Incorporating Graphene Oxide and Gold Nanoclusters: A Synergistic Catalyst with Surprisingly High Peroxidase-Like Activity Over a Broad pH Range and Its Application for Cancer Cell Detection. Adv. Mater. 2013, 25, 25942599.

(30) Zhang, S.; Zhao, X.; Niu, H.; Shi, Y.; Cai, Y.; Jiang, G. Superparamagnetic $\mathrm{Fe}_{3} \mathrm{O}_{4}$ Nanoparticles as Catalysts for the Catalytic Oxidation of Phenolic and Aniline Compounds. J. Hazard. Mater. 2009, $167,560-566$.

(31) Hu, L.; Yuan, Y.; Zhang, L.; Zhao, J.; Majeed, S.; Xu, G. Copper Nanoclusters as Peroxidase Mimetics and Their Applications to $\mathrm{H}_{2} \mathrm{O}_{2}$ and Glucose Detection. Anal. Chim. Acta 2013, 762, 83-86.

(32) Asati, A.; Santra, S.; Kaittanis, C.; Nath, S.; Perez, J. M. OxidaseLike Activity of Polymer-Coated Cerium Oxide Nanoparticles. Angew. Chem., Int. Ed. 2009, 48, 2308-2312.

(33) Luo, W.; Zhu, C.; Su, S.; Li, D.; He, Y.; Huang, Q.; Fan, C. SelfCatalyzed, Self-Limiting Growth of Glucose Oxidase-Mimicking Gold Nanoparticles. ACS Nano 2010, 4, 7451-7458.

(34) Chaudhari, K. N.; Chaudhari, N. K.; Yu, J.-S. Peroxidase Mimic Activity of Hematite Iron Oxides $\left(\alpha-\mathrm{Fe}_{2} \mathrm{O}_{3}\right)$ with Different Nanostructures. Catal. Sci. Technol. 2012, 2, 119-124. 
(35) Lee, J. W.; Jeon, H. J.; Shin, H.-J.; Kang, J. K. Superparamagnetic $\mathrm{Fe}_{3} \mathrm{O}_{4}$ Nanoparticles-Carbon Nitride Nanotube Hybrids for Highly Efficient Peroxidase Mimetic Catalysts. Chem. Commun. 2012, 48, 422424.

(36) Chen, W.; Chen, J.; Feng, Y.-B.; Hong, L.; Chen, Q.-Y.; Wu, L.-F.; Lin, X.-H.; Xia, X.-H. Peroxidase-Like Activity of Water-Soluble Cupric Oxide Nanoparticles and Its Analytical Application for Detection of Hydrogen Peroxide and Glucose. Analyst 2012, 137, 1706-1712.

(37) Asati, A.; Kaittanis, C.; Santra, S.; Perez, J. M. pH-Tunable Oxidase-Like Activity of Cerium Oxide Nanoparticles Achieving Sensitive Fluorigenic Detection of Cancer Biomarkers at Neutral pH. Anal. Chem. 2011, 83, 2547-2553.

(38) Wan, Y.; Qi, P.; Zhang, D.; Wu, J.; Wang, Y. Manganese Oxide Nanowire-Mediated Enzyme-Linked Immunosorbent Assay. Biosens. Bioelectron. 2012, 33, 69-74.

(39) Karakoti, A. S.; Singh, S.; Kumar, A.; Malinska, M.; Kuchibhatla, S. V. N. T.; Wozniak, K.; Self, W. T.; Seal, S. PEGylated Nanoceria as Radical Scavenger with Tunable Redox Chemistry. J. Am. Chem. Soc. 2009, 131, 14144-14145.

(40) He, W.; Liu, Y.; Yuan, J.; Yin, J.-J.; Wu, X.; Hu, X.; Zhang, K.; Liu, J.; Chen, C.; Ji, Y.; Guo, Y. Au@Pt Nanostructures as Oxidase and Peroxidase Mimetics for Use in Immunoassays. Biomaterials 2011, 32, 1139-1147.

(41) Yu, C.-J.; Lin, C.-Y.; Liu, C.-H.; Cheng, T.-L.; Tseng, W.-L. Synthesis of Poly(diallyldimethylammonium chloride)-Coated $\mathrm{Fe}_{3} \mathrm{O}_{4}$ Nanoparticles for Colorimetric Sensing of Glucose and Selective Extraction of Thiol. Biosens. Bioelectron. 2010, 26, 913-917.

(42) Kaittanis, C.; Santra, S.; Perez, J. M. Role of Nanoparticle Valency in the Nondestructive Magnetic-Relaxation-Mediated Detection and Magnetic Isolation of Cells in Complex Media. J. Am. Chem. Soc. 2009, 131, 12780-12791.

(43) Gao, L.; Zhuang, J.; Nie, L.; Zhang, J.; Zhang, Y.; Gu, N.; Wang, T.; Feng, J.; Yang, D.; Perrett, S.; Yan, X. Intrinsic Peroxidase-Like Activity of Ferromagnetic Nanoparticles. Nat. Nanotechnol. 2007, 2, 577-583.

(44) Zhang, X.-Q.; Gong, S.-W.; Zhang, Y.; Yang, T.; Wang, C.-Y.; Gu, N. Prussian Blue Modified Iron Oxide Magnetic Nanoparticles and Their High Peroxidase-Like Activity. J. Mater. Chem. 2010, 20, 51105116.

(45) Wang, H.; Huang, Y. Prussian-Blue-Modified Iron Oxide Magnetic Nanoparticles as Effective Peroxidase-Like Catalysts to Degrade Methylene Blue with $\mathrm{H}_{2} \mathrm{O}_{2}$. J. Hazard. Mater. 2011, 191, 163-169.

(46) Liu, J.; Hu, X.; Hou, S.; Wen, T.; Liu, W.; Zhu, X.; Yin, J.-J.; Wu, X. $\mathrm{Au} @ \mathrm{Pt}$ Core/Shell Nanorods with Peroxidase- and Ascorbate OxidaseLike Activities for Improved Detection of Glucose. Sensors Actuators B: Chem. 2012, 166-167, 708-714.

(47) Yu, F.; Huang, Y.; Cole, A. J.; Yang, V. C. The Artificial Peroxidase Activity of Magnetic Iron Oxide Nanoparticles and its Application to Glucose Detection. Biomaterials 2009, 30, 4716-4722.

(48) Fan, Y.; Huang, Y. The Effective Peroxidase-Like Activity of Chitosan-Functionalized $\mathrm{CoFe}_{2} \mathrm{O}_{4}$ Nanoparticles for Chemiluminescence Sensing of Hydrogen Peroxide and Glucose. Analyst 2012, 137, $1225-1231$.

(49) Lee, Y.; Garcia, M. A.; Frey Huls, N. A.; Sun, S. Synthetic Tuning of the Catalytic Properties of $\mathrm{Au}-\mathrm{Fe}_{3} \mathrm{O}_{4}$ Nanoparticles. Angew. Chem., Int. Ed. 2010, 49, 1271-1274.

(50) Liu, Z.; Zhao, B.; Shi, Y.; Guo, C.; Yang, H.; Li, Z. Novel Nonenzymatic Hydrogen Peroxide Sensor Based on Iron Oxide-Silver Hybrid Submicrospheres. Talanta 2010, 81, 1650-1654.

(51) Chen, Z.; Yin, J.-J.; Zhou, Y.-T.; Zhang, Y.; Song, L.; Song, M.; Hu, S.; Gu, N. Dual Enzyme-Like Activities of Iron Oxide Nanoparticles and Their Implication for Diminishing Cytotoxicity. ACS Nano 2012, 6, 4001-4012.

(52) Li, C.; Sun, L.; Sun, Y.; Teranishi, T. One-Pot Controllable Synthesis of Au@Ag Heterogeneous Nanorods with Highly Tunable Plasmonic Absorption. Chem. Mater. 2013, 25, 2580-2590.

(53) Wang, F.; Liu, P.; Sun, L.; Li, C.; Petrenko, V. A.; Liu, A. Biomimetic Nanostructure Self-assembled from Au@Ag Heterogeneous
Nanorods and Phage Fusion Proteins for Targeted Tumor Optical Detection and Photothermal Therapy. Sci. Rep. 2014, 4, 6808.

(54) Li, C.; Shuford, K. L.; Chen, M.; Lee, E. J.; Cho, S. O. A Facile Polyol Route to Uniform Gold Octahedra with Tailorable Size and Their Optical Properties. ACS Nano 2008, 2, 1760-1769.

(55) Rai, N. K.; Rai, A. K. LIBS-An Efficient Approach for the Determination of $\mathrm{Cr}$ in Industrial Wastewater. J. Hazard. Mater. 2008, $150,835-838$.

(56) Yang, X.; Wang, Y.; Liu, Y.; Jiang, X. A Sensitive Hydrogen Peroxide and Glucose Biosensor Based on Gold/Silver Core-Shell Nanorods. Electrochim. Acta 2013, 108, 39-44.

(57) Liu, M.; Guyot-Sionnest, P. Synthesis and Optical Characterization of $\mathrm{Au} / \mathrm{Ag}$ Core/Shell Nanorods. J. Phys. Chem. B 2004, 108, $5882-5888$.

(58) Okuno, Y.; Nishioka, K.; Kiya, A.; Nakashima, N.; Ishibashi, A.; Niidome, Y. Uniform and Controllable Preparation of Au-Ag Core-Shell Nanorods Using Anisotropic Silver Shell Formation on Gold Nanorods. Nanoscale 2010, 2, 1489-1493.

(59) Zhang, S.; Han, L.; Hou, C.; Li, C.; Lang, Q.; Han, L.; Liu, A. Novel Glucose Sensor with Au@Ag Heterogeneous Nanorods Based on Electrocatalytic Reduction of Hydrogen Peroxide at Negative Potential. J. Electroanal. Chem. 2015, 742, 84-89.

(60) Ah, C. S.; Hong, S. D.; Jang, D.-J. Preparation of $\mathrm{Au}_{\text {core }} \mathrm{Ag}_{\text {shell }}$ Nanorods and Characterization of Their Surface Plasmon Resonances. J. Phys. Chem. B 2001, 105, 7871-7873.

(61) Schonbaum, G. R.; Lo, S. Interaction of Peroxidases with Aromatic Peracids and Alkyl Peroxides: Product Analysis. J. Biol. Chem. 1972, 247, 3353-3360.

(62) Rodríguez-López, J. N.; Gilabert, M. A.; Tudela, J.; Thorneley, R. N. F.; García-Cánovas, F. Reactivity of Horseradish Peroxidase Compound II toward Substrates: Kinetic Evidence for a Two-Step Mechanism. Biochemistry 2000, 39, 13201-13209.

(63) Hsueh, C. L.; Huang, Y. H.; Wang, C. C.; Chen, C. Y. Degradation of Azo Dyes Using Low Iron Concentration of Fenton and Fenton-Like System. Chemosphere 2005, 58, 1409-1414.

(64) Song, Y.; Wei, W.; Qu, X. Colorimetric Biosensing Using Smart Materials. Adv. Mater. 2011, 23, 4215-4236.

(65) Peng, F. F.; Zhang, Y.; Gu, N. Size-Dependent Peroxidase-Like Catalytic Activity of $\mathrm{Fe}_{3} \mathrm{O}_{4}$ Nanoparticles. Chin. Chem. Lett. 2008, 19, $730-733$.

(66) Wang, S.; Chen, W.; Liu, A.-L.; Hong, L.; Deng, H.-H.; Lin, X.-H. Comparison of the Peroxidase-Like Activity of Unmodified, AminoModified, and Citrate-Capped Gold Nanoparticles. ChemPhysChem 2012, 13, 1199-1204.

(67) He, W.; Wu, X.; Liu, J.; Hu, X.; Zhang, K.; Hou, S.; Zhou, W.; Xie, S. Design of AgM Bimetallic Alloy Nanostructures $(M=A u, P d, P t)$ with Tunable Morphology and Peroxidase-Like Activity. Chem. Mater. 2010, 22, 2988-2994

(68) Jo, S.-M.; Lee, H. Y.; Kim, J.-C. Glucose-Sensitivity of Liposomes Incorporating Conjugates of Glucose Oxidase and Poly(N-isopropylacrylamide-co-methacrylic Acid-co-octadecylacrylate). Int. J. Biol. Macromol. 2009, 45, 421-426.

(69) Kalisz, H. M.; Hecht, H.-J.; Schomburg, D.; Schmid, R. D. Crystallization and Preliminary X-ray Diffraction Studies of a Deglycosylated Glucose Oxidase From Aspergillus niger. J. Mol. Biol. 1990, 213, 207-209.

(70) Simpson, C.; Jordaan, J.; Gardiner, N. S.; Whiteley, C. Isolation, Purification and Characterization of a Novel Glucose Oxidase from Penicillium sp. CBS 120262 Optimally Active at Neutral pH. Protein Expression Purif. 2007, 51, 260-266. 